\title{
Oxidative stress in fetal distress Potential prospects for diagnosis
}

\author{
Saša Raičević, ${ }^{1}$ Dejan Čubrilo, ${ }^{2}$ Slobodan Arsenijević, ${ }^{3}$ Gordana Vukčevic, ${ }^{1}$ Vladimir Živković, ${ }^{2}$ Milena Vuletić, ${ }^{2}$ \\ Nevena Barudžić, ${ }^{2}$ Nebojša Andjelković, ${ }^{4}$ Olga Antonović ${ }^{5}$ and Vladimir Jakovljevićz ${ }^{2 * *}$ \\ 'Clinic of Gynecology and Obstetrics; Clinical Centre of Montenegro; Podgorica, Montenegro; ${ }^{2}$ Department of Physiology; Faculty of Medicine; University of Kragujevac; \\ Kragujevac, Serbia; ${ }^{3}$ Clinic of Gynecology and Obstetrics; and "Department of Haematology Internal Clinic; Clinical Centre "Kragujevac"; Faculty of Medicine; \\ University of Kragujevac; Kragujevac, Serbia; ${ }^{5}$ Department of Neonatology; Institute for Gynecology and Obstetrics; Clinical Centre of Serbia; Belgrade, Serbia
}

Key words: fetal distress, oxidative stress, catalase, superoxide dismutase

Our aim was to investigate the relation between fetal distress and oxidative stress. Fetal distress was associated with increased concentration of superoxide in the fetal blood and with significant increase of the level of $\mathrm{H}_{2} \mathrm{O}_{2}$ in both maternal and fetal blood. The activity of superoxide dismutase was increased roughly sixfold $(p<0.01)$ in the maternal [7330 $\pm 2240 \mathrm{U} / \mathrm{g}$ of hemoglobin in controls (C) and $36811 \pm 16862 \mathrm{U} / \mathrm{g}$ in fetal distress (FD)] and fetal blood (C: $5930 \pm 2641$ U/g; FD: $41912 \pm 17133 \mathrm{U} / \mathrm{g}$ ). In contrast, fetal distress was related to a considerable decrease of catalase activity in both maternal (C: $26011 \pm 8811 \mathrm{U} / \mathrm{g} ;$ FD: $7212 \pm 1270 \mathrm{U} / \mathrm{g}$ ) and fetal blood (C: $37194 \pm 9191 \mathrm{U} / \mathrm{g} ;$ FD: $6173 \pm 1965 \mathrm{U} / \mathrm{g}$ ). From this we concluded that in fetal distress, the maternal and fetal bloods are exposed to superoxide- and $\mathrm{H}_{2} \mathrm{O}_{2}$-mediated oxidative stress, which could be initiated by hypoxic conditions in the fetal blood and placenta. A tremendous increase/decrease of the activities of superoxide dismutase/catalase in the blood of women bearing a distressed fetus in comparison to healthy subjects implies that the assessment of superoxide dismutase/catalase activity could be of use for establishing a timely and accurate ante- or intrapartum diagnosis of fetal distress.

\section{Introduction}

Fetal distress represents a pathophysiological condition in which oxygen is not available to the fetus in sufficient quantities. ${ }^{1}$ If not corrected or circumvented, it may result in decompensation of the physiological responses and even cause multiple organ damage., ${ }^{2,3}$ Fetal distress is intrinsically associated with fetal hypoxia and acidosis, and it seems to be strongly related to perinatal asphyxia. ${ }^{4-6}$ The management of fetal distress involves intensive monitoring, intrauterine resuscitation, amnioninfusion and immediate delivery by vaginal route or caesarian section. ${ }^{4,7,8}$ The postpartum diagnosis of fetal distress is based on low $\mathrm{pH}$ value of cord blood, ${ }^{9-11}$ depressed Apgar score, and other parameters. ${ }^{5,12}$ However ante- and intrapartum prediction, which is crucial for an appropriate treatment of the condition, is far from being straightforward. Because of the low positive predictive value, ACOG Committee on Obstetrics Practice has recommended that the term fetal distress as an ante- and intrapartum diagnosis should be replaced with "nonreassuring fetal status." Several ante- and intrapartum markers of fetal distress are currently available, such as an abnormal fetal heart rate (repetitive late decelerations, undulating baseline, bradycardia), decreased $\mathrm{pO}_{2}$ in the fetal blood, meconium-staining of amniotic fluid, and low $\mathrm{pH}$ value or increased lactate in the fetal scalp. ${ }^{12,14,15}$ However, it seems that novel diagnostic procedures should be developed and added to the list, in order to increase the value of positive prediction of fetal distress.

Oxidative stress represents disbalance between production of various reactive oxygen species (ROS) and activity of endogenous antioxidative defance system (ADS). It is involved in pathophysiology of more then 200 diseases ${ }^{16,17}$ including aging ${ }^{18-20}$ and oxidative damage in extreme physiological stages (exercise, diving, climbing). ${ }^{21,22}$ Fetal distress could be associated with oxidative stress in fetal and maternal blood, since hypoxia, which represents a hallmark of this pregnancy complication, ${ }^{14,23}$ is known to provoke increased production of reactive oxygen species (ROS). ${ }^{24}$ Dede and co-workers have recently reported that SOD activity and the level of lipid peroxidation in umbilical cord blood are increased in nonreassuring fetal status. ${ }^{25}$ In addition, antioxidative treatment has shown some protective effects in fetal distress. ${ }^{26,27}$ In the present study we have compared the oxidative status of blood of mothers and neonates with fetal distress to the status of blood in normal pregnancies. Oxidative status was evaluated by measuring the levels of superoxide and hydrogen peroxide in plasma and the activities of corresponding antioxidative enzymes - superoxide dismutase and catalase in erythrocytes obtained from 22 mothers and neonates with fetal distress and 24 control subjects. The aim was to determine the relation between fetal distress and oxidative stress and to explore potential prospects for the application of specific biochemical assays for oxidative status parameters as diagnostic tools for fetal distress prediction. 


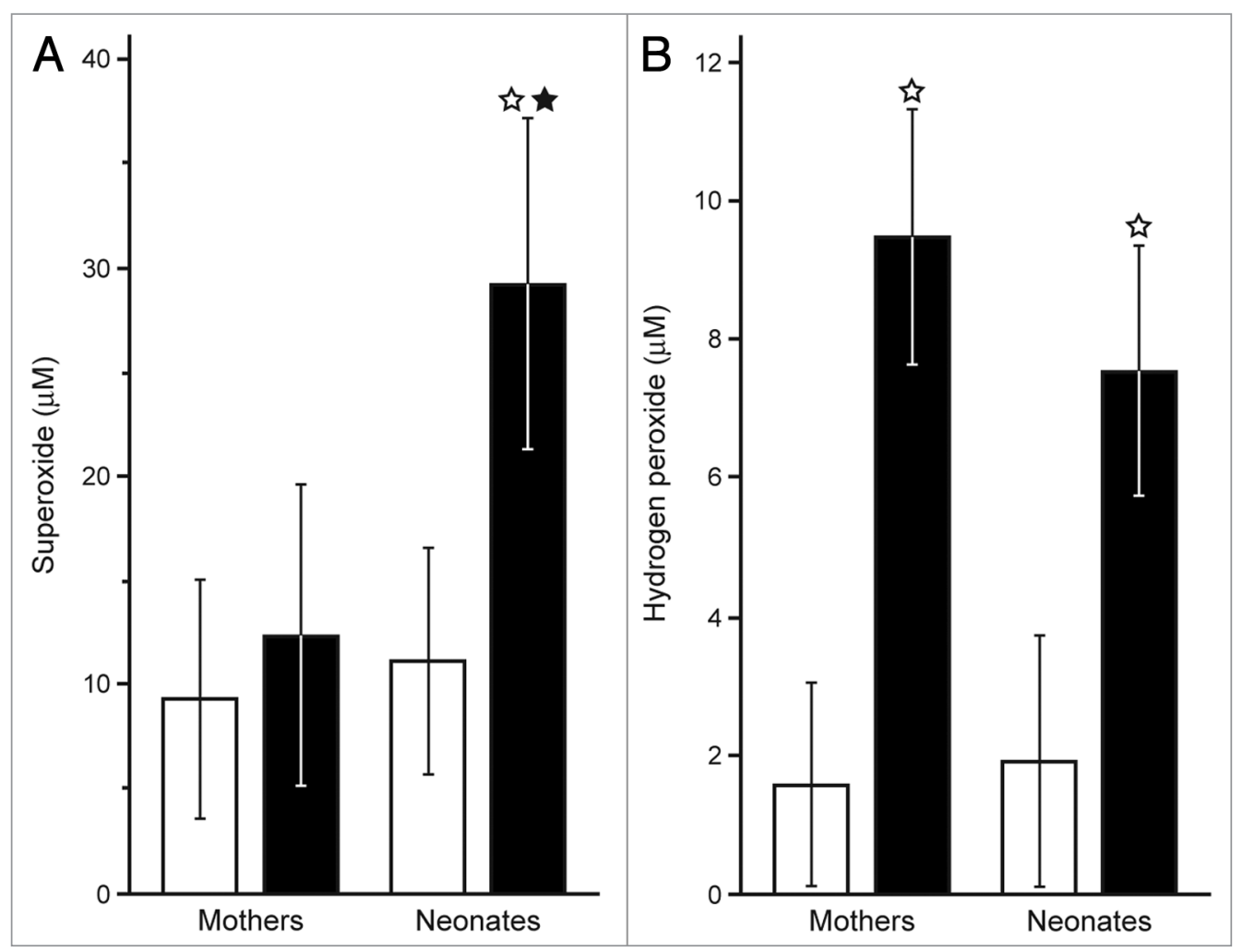

Figure 1. Differences in concentrations of superoxide (left, A) and hydrogen peroxide (right, B) in maternal and neonatal plasma [In micromolar range, $\mu \mathrm{M}(\mu \mathrm{mol} / \mathrm{l}$ plasma)] suffering from fetal distress (FD) compared to control. Results are presented as means \pm S.D. Controls, white columns; FD, black columns. The values of superoxide $(\mu \mathrm{M})$ were: $9.10 \pm 5.95$ (Med 6.91) in control maternal plasma; $10.86 \pm 5.55$ (Med 11.86 ) in control fetal plasma; 12.12 \pm 7.32 (Med 9.56) in FD maternal plasma; $29.02 \pm 38.43$ (Med 16.47). White star, statistically significant when compared to controls ( $p<0.01$ ); Black star, statistically significant when compared to maternal plasma level $(p<0.05)$.

\section{Results}

Figure 1 shows the concentration of ROS in the plasma of mothers and neonates with fetal distress in comparison to controls. The level of superoxide was significantly increased in the plasma of distressed babies (Fig. 1A), while blood level of $\mathrm{H}_{2} \mathrm{O}_{2}$ was increased both in mothers and neonates with fetal distress (Fig. 1B). Superoxide concentration in the plasma of distressed neonates was notably higher than in maternal plasma. On the other hand the level of $\mathrm{H}_{2} \mathrm{O}_{2}$ was similar in the plasmas of distressed neonates and their mothers. The activities of superoxide dismutating and $\mathrm{H}_{2} \mathrm{O}_{2}$-scavenging enzymes (SOD and catalase) are shown in Figure 2. SOD was several times more active in the erythrocytes of fetal distress neonates and mothers than in controls (Fig. 2A), while reverse ratio was observed for catalase (Fig. 2B).

\section{Discussion}

The findings demonstrate that maternal and fetal bloods are exposed to oxidative stress in fetal distress. It seems that oxidative stress is predominantly of fetal origin, since the concentration of superoxide was increased only in the fetal plasma. However, high SOD activity in the maternal blood indicates that some superoxide production may also develop in maternal tissues. In line with this is the fact that placental tissue of patients with nonreassuring fetal status is exposed to oxidative stress and shows significantly increased SOD activity. ${ }^{25}$ Superoxide is dismutated to $\mathrm{H}_{2} \mathrm{O}_{2}$ which can pass from the fetal into the maternal blood and vice versa, resulting in similar $\mathrm{H}_{2} \mathrm{O}_{2}$ concentrations in these two tissues, which is in accordance with previously established good correlation between maternal and fetal oxidative statuses. ${ }^{28}$ However, observed increase of the level of $\mathrm{H}_{2} \mathrm{O}_{2}$ was not accompanied by promoted activity of $\mathrm{H}_{2} \mathrm{O}_{2}$-scavenging enzyme catalase. The enzymatic activity of the first step (SOD) and second step (GSH/Px and/or CAT) have to be balanced to prevent cell damage. Any increase in SOD activity produces an excess of $\mathrm{H}_{2} \mathrm{O}_{2}$ that must be efficiently neutralized by either GSH-Px or CAT (Fig. 3). In fact catalase activity was significantly reduced in fetal distress, which could be explained by NO-mediated catalase inhibition. ${ }^{29,30}$ Nevertheless, reduced CAT activity in our study could be explained by changed antioxidant defence system for $\mathrm{H}_{2} \mathrm{O}_{2}$ neutralisation in erythrocytes, regarding to aknowledge that exist reduced GSH-Px and CAT activity in serbian population. ${ }^{31}$ Those changes were explained by selen deficiency occurred in Serbia region..$^{32}$ It is not uncommon that antioxidant defence systems are altered in response to various diseases. ${ }^{33,34}$ The limitation of our study is that we did not investigate some plasma lipid components and its relationds to oxidative stress. Few recent data represents possible significant interaction between 


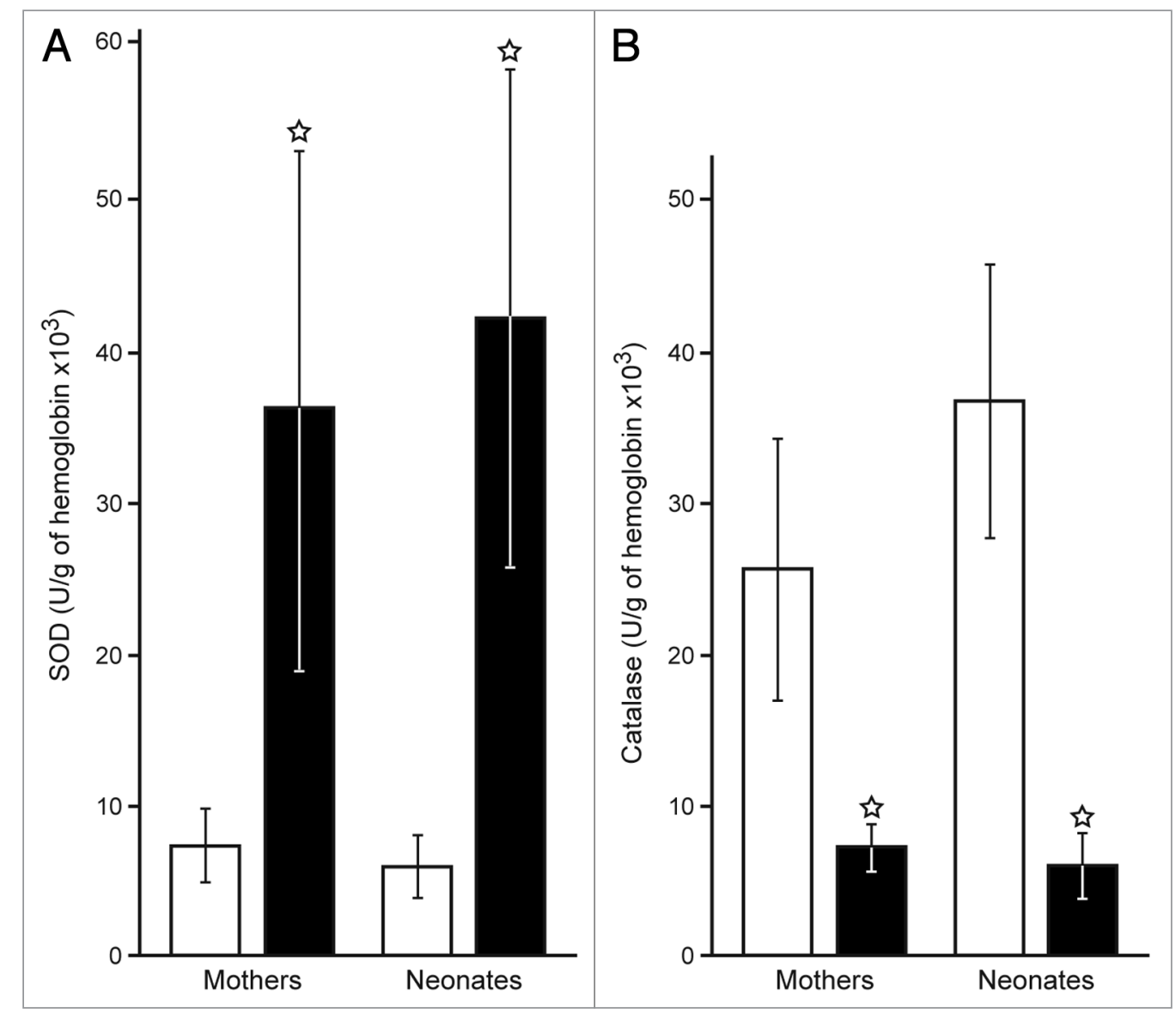

Figure 2. Differences in activity of SOD (left, A) and catalase (right, B) in maternal and neonatal erythrocytes (Expressed as U/g Hemoglobin $x 10^{3}$ ) suffering from fetal distress (FD) compared to control. Results are presented as means \pm S.D. Controls, white columns; (FD), black columns. The values of SOD activity ( $\times 10^{3} \mathrm{U} / \mathrm{g}$ of hemoglobin) were within the following limits: 3.86-11.67 in control maternal erythrocytes; 16.27-89.54 in FD maternal erythrocytes; $1.49-11.22$ in control fetal erythrocytes; $16.28-75.12$ in FD fetal erythrocytes. The values of catalase activity (x10 $\mathrm{U} / \mathrm{g}$ of hemoglobin) were within the following limits: 13.58-44.71 in control maternal erythrocytes: 5.62-9.79 in FD maternal erythrocytes; $26.44-48.42$ in control fetal erythrocytes; 1.02-8.77 in FD fetal erythrocytes. White star, statistically significant when compared to controls $(p<0.01)$.

serum cholesterol $(\mathrm{Ch})$ and membrane phospholipids with $\mathrm{Hb}$ in human erythrocytes (Hb-Ch), what could be a significant factor for the organization of the antioxidant defence system in erythrocytes of mother and neonates with fetal distress. ${ }^{34}$ Further randomized multicenter studies should be performed to clarify the relationship among lipids, selenium and NO concentration, as well as antioxidant enzymes activity in fetal distress pathogenesis. The lower SOD activity in erythrocytes of mothers compared to neonates with fetal distress in our study could be explained by $\mathrm{H}_{2} \mathrm{O}_{2}$-induced inhibition of SOD activity, what is in correlation with recent data. ${ }^{35}$ Hence, our results indirectly imply that fetal distress is characterized not only by increased ROS production, but also by increased blood level of $\mathrm{NO}$ and its derivatives. It should be noted that the number of deliveries by caesarian section was significantly higher in the study group. However, this could not account for presented results, since caesarian section was reported not to affect SOD activity and to provoke only modest a decrease of activity of catalase in the cord blood. ${ }^{36}$

Increased ROS production and decreased catalase activity could represent a consequence of hypoxia of the fetal blood. ${ }^{37,38}$
The hypoxia of blood may provoke increased ROS generation in the mitochondria of endothelial and placental cells, ${ }^{39}$ but some other mechanisms of oxidative stress are also plausible, such as the modulation of leukocytes activity, ${ }^{40}$ or promoted activity of endothelial NADPH oxidase. ${ }^{41}$ Independently of the mechanisms, increased ROS production in the fetal blood could explain some of the symptoms of fetal distress. Hydrogen peroxide has been reported to provoke relaxation of sphincter muscles, ${ }^{42}$ so increased level of $\mathrm{H}_{2} \mathrm{O}_{2}$ in the blood of distressed fetuses could be responsible for the release of meconium into the amniotic fluid. Furthermore, ROS can affect normal function of the fetal cardiovascular system. It has been reported that ROS provoke relaxation of ductus arteriosus by stimulating prostaglandin synthesis. ${ }^{43}$ Hydrogen peroxide is known to exert a dose-dependent biphasic effects on human heart, provoking an increase of contractile force followed by a decrease..$^{44}$ In another study, an injection of $\mathrm{H}_{2} \mathrm{O}_{2}$ was observed to provoke bradycardia and hypotension in rats. ${ }^{45}$ Therefore, increased blood level of $\mathrm{H}_{2} \mathrm{O}_{2}$ and superoxide could be at least partially responsible for abnormalities of the heart rate which are characteristic for fetal distress. 


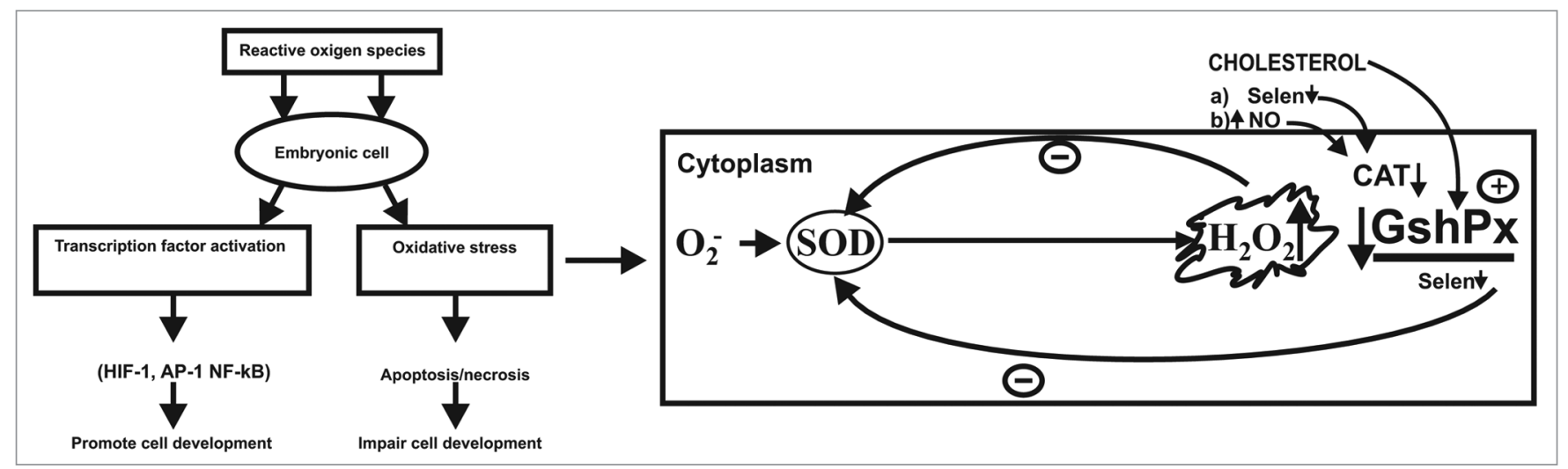

Figure 3. (Left) The role of oxidative stress in fetal distress: How ROS can be involved in cell damage/survival. $\mathrm{O}_{2}$; superoxidanion radical; SOD, superoxiddismutase; $\mathrm{H}_{2} \mathrm{O}_{2}$, hydrogen peroxide; GSHPx, glutathione reductase; CAT, catalase; NO, niricoxide.

Table 1. Baseline clinical characteristics of the study and control group

\begin{tabular}{|c|c|c|}
\hline & $\begin{array}{l}\text { Control } \\
(n=24)\end{array}$ & $\begin{array}{l}\text { Fetal distress } \\
\quad(n=22)\end{array}$ \\
\hline Maternal age (years) & $27.7 \pm 5.0$ & $30.5 \pm 4.8^{*}$ \\
\hline Gestational age (weeks) & $39.1 \pm 1.6$ & $35.7 \pm 2.8^{*}$ \\
\hline Neonate weight (g) & $3371 \pm 614$ & $2345 \pm 794^{*}$ \\
\hline Smokers (n (\%)) & $1(4.3 \%)$ & $1(4.5 \%)$ \\
\hline Caesarian section & $1(4.3 \%)$ & $8(36.4 \%)^{*}$ \\
\hline \multicolumn{3}{|l|}{ pregnancy complications } \\
\hline ture rupture of the membrane & 0 & $4(18.1 \%)^{*}$ \\
\hline nancy induced hypertension & 0 & $4(18.1 \%)^{*}$ \\
\hline $\begin{array}{l}\text { terine growth restriction }\left(<10^{\text {th }}\right. \\
\text { adjusted centile) }\end{array}$ & 0 & $3(13.6 \%)^{*}$ \\
\hline Pre-eclampsia & 0 & $1(4.5 \%)$ \\
\hline Olygohydraminos & 0 & $1(4.5 \%)$ \\
\hline
\end{tabular}

*statistically significant.

The identification of patients at risk for the development of fetal distress prior or during labor is among the major points in perinatal medicine. The fact that $\mathrm{SOD} /$ catalase activities are tremendously increased/decreased in the blood of women bearing a distressed fetus could be of use for establishing a timely and accurate ante- or intrapartum diagnosis of fetal distress. It should be stressed that observed settings of antioxidative system of maternal blood in fetal distress have not been reported for any other pregnancy complication to date. Therefore, we propose that, in addition to other available procedures, the screening of the activities of SOD and catalase should be performed on maternal blood in the case of nonreassuring fetal status, in order to improve the value of positive antepartum predication of fetal distress. The postpartum diagnostic could also be improved by measuring SOD and catalase activity in the cord blood. Although further validation in clinical trails is necessary, it seems that a combination of increased SOD activity and decreased catalase activity of in the maternal blood could represent a valuable ante- and intrapartum marker of fetal distress.

\section{Patients and Methods}

Patients. Our study included 22 pregnancies with fetal distress (study group) and 24 normal pregnancies (control group). The maternal and neonatal clinical characteristics are presented in Table 1.

Inclusion/exclusion criteria. Pregnant women with a gestational age of at least 36 weeks and suspected intra-uterine hypoxia (fetal distress) during labour can be included in the trial. Fetal distress is being diagnosed by the clinician as an abnormal or nonreassuring fetal heart rate trace, preferably accompanied by either significant ST-wave abnormalities (as detected by the STAN-monitor) or an abnormal fetal blood scalp sampling $(\mathrm{pH}<7.20)$ and one- and five-minute Apgar score $(<7) ., 12,46$ Neonates suspected of chromosomal or congenital anomalies were excluded. The value of cord blood $\mathrm{pH}$ and Apgar scores for control group were $>7.25$ and $8-10$, respectively. Institutional approval for the study was granted by The Clinics Ethics Committee in accordance with internationally accepted ethical standards (The Helsinki Declaration of 1964, last revised in 2005). The antenatal clinics gave information about the study to women in late pregnancy and requested consent at this time or when the woman was admitted in labor. If consent was not given, or if the woman was too distressed to be asked for consent, she was managed according to the standard protocols of the departments.

Samples. Maternal and umbilical cord blood samples were taken immediately after the delivery in commercial containers filled with heparin $(50 \mathrm{U} / \mathrm{ml}$ of blood). Plasma was separated from erythrocytes by centrifugation at $5,000 \mathrm{rpm}$ at $4^{\circ} \mathrm{C}$ for $10 \mathrm{~min}$. Erythrocytes were washed three times with $0.9 \% \mathrm{NaCl}$. All samples were immediately frozen in liquid nitrogen and kept at $-85^{\circ} \mathrm{C}$ until further analysis.

Spectrophotometric assays. The concentration of superoxide in plasma was measured as described previously. ${ }^{47}$ Hydrogen peroxide was detected according to Pick and Keisari. ${ }^{48}$ Erythrocytes $(0.5 \mathrm{ml})$ were lysed by adding $3 \mathrm{ml}$ of ice-cold distilled water. Hemoglobin concentration was measured by the Drabkin method. The activity of SOD was measured according to the 
method of Misra and Fridovich. ${ }^{49}$ Previously described method was used to determine the activity of catalase..$^{50}$ All the chemicals used in this study were purchased from Merck (Darmstadt, Germany) and Sigma-Aldrich (St. Louis, MO, USA).

Statistical analysis. Measurements were performed on one sample of maternal and fetal plasma and erythrocytes lysates obtained from each patient. Statistical differences were evaluated by means of the non-parametric two-tailed Mann-Whitney test using Statistica 6.0 (StatSoft Inc., Tulsa, OK, USA). Results are presented as means \pm S.D. (standard deviation) and were taken to be statistically different if $\mathrm{p}<0.05$.

\section{Acknowledgements}

This work was supported by the Grant No. 145014 from the Ministry of Science and Technical Development of the Republic of Serbia.

\section{References}

1. Harris AP. Sudden fetal distress. In: Datta S, ed. Common Problems in Obstetric Anesthesia. St. Louis, MO: Mosby 1995; 263-77.

2. Parer JT, Livingston EG. What is fetal distress? Am J Obstet Gynecol 1990; 162:1421-5.

3. Low JA, Panagiotopolous C, Derrick EJ. Newborn complications after intrapartum asphyxia with metabolic acidosis in the term fetus. Am J Obstet Gynecol 1994; 170:1081-7

4. Thurlow JA, Kinsella SM. Intrauterine resuscitation: active management of fetal distress. Int J Obst Anesth 2002; 11:105-16.

5. Harris AP, Witter FR. Fetal distress. In: Datta S, ed. Anesthetic and Obstetric Management of High-Risk Pregnancy. New York: Springer-Verlag Inc 2004; 491-503.

6. Bano S, Chaudhary V, Pande S, Mehta V, Sharma A. Color doppler evaluation of cerebral-umbilical pulsatility ratio and its usefulness in the diagnosis of intrauterine growth retardation and prediction of adverse perinatal outcome. Indian J Radiol Imaging 2010; 20:20-5.

7. Vigil-De Gracia P, Simití E, Lora Y. Intrapartum fetal distress and magnesium sulfate. Int J Gynecol Obstet 2000; 68:3-6.

8. Sochaczewska D, Czeszynska Maria B, Konefał H, Elster T, Baryła-Pankiewicz E. Assessment of relationship between cord blood cotinine levels and some factors of perinatal hypoxia. Ginekol Pol 2009; 80:920-6.

9. Sykes GS, Johnson P, Ashworth F, Molloy PM, Gu W, Stirrat GM, et al. Do Apgar scores indicate asphyxia? Lancet 1982; 1:494-6.

10. Nonnenmacher A, Hopp H, Dudenhausen J. Predictive value of pulse oximetry for the development of fetal acidosis. J Perinat Med 2010; 38:83-6.

11. Abessolo FO, Ngou JP, Meye JF, Yangou JM, Lemamy GJ, Ngou-Milama EJ. Fetal distress: Information provided by lactate levels and antioxidant status, compared with the Apgar score. Sante 2009; 19:15-9.

12. Wiberg-Itzel E, Lipponer C, Norman M, Herbst A, Prebensen D, Hansson A, et al. Determination of $\mathrm{pH}$ or lactate in fetal scalp blood in management of intrapartum fetal distress: randomized controlled multicentre trial. Br Med J 2008: 336:1284-7.

13. ACOG Committee on Obstetric Practice. Inappropriate use of the terms fetal distress and birth asphyxia. Obstet Gynecol 2005; 106:1469-70.

14. Steer PJ. Fetal distress. Curr Obstet Gynaecol 2002; 12:15-21.

15. Tharmaratnam S. Fetal distress. Bailliére's Clin Obstet Gynaecol 2000; 14:155-72.

16. Saicic Z. Antioxidative defance system. In: Atheroslerosis (Risk factors, pathogenesis, therapy and prevention). Djuric DM, (ed), Serbian Physiological Society 2005; 45-61.

17. Gomes P, Simão S, Silva E, Pinto V, Amaral JS, Afonso $\mathrm{J}$, et al. Aging increases oxidative stress and renal expression of oxidant and antioxidant enzymes that are associated with an increased trend in systolic blood pressure. Oxid Med Cell Longev 2009; 2:138-45.

18. Elahi MM, Kong Y, Matata B. Oxidative stress as a mediator of cardiovascular disease. Oxid Med Cell Longev 2009; 2:259-69.
19. Pandey K, Rizvi SI. Markers of oxidative stress in erythrocytes and plasma during aging in humans. Oxid Med Cell Longev 2010; 3:1-11.

20. Maiese K. Heal thyself: Endogenous pathways of protection for oxidative stress. Oxid Med Cell Longev 2010; 3:75-76.

21. Tepic S, Zivkovic M, Terzic N, Krivokuca R, Ljesevic B, Jakovljevic V. Effect of hyperbaric oxygen treatment on oxidative stress in patients having diabetes mellitus type 2. Med Rev 2009; 62:225-30.

22. Jakovljevic V, Zlatkovic M, Cubrilo D, Pantic I, Djuric DM. The effects of progressive exercise on cardiovascular function in elite athletes: Focus on oxidative stress. Acta Phys Hun 2011; In press.

23. Torrance HL, Krediet TG, Vreman HJ, Visser GH, van Bel F. Oxidative stress and proinflammatory cytokine levels are increased in premature neonates of preeclamptic mothers with HELLP syndrome. Neonatology 2008; 94:138-42.

24. Fresquet F, Pourageaud F, Leblais V, Brandes RP, Savineau J-P, Marthan R, et al. Role of reactive oxygen species and gp91phox in endothelial dysfunction of pulmonary arteries induced by chronic hypoxia. Br J Pharmacol 2006; 148:714-23.

25. Dede FS, Guney Y, Dede H, Koca C, Dilbaz B, Bilgihan A. Lipid peroxidation and antioxidant activity in patients in labor with nonreassuring fetal status. Eur J Obstet Gynecol Reprod Biol 2006; 124:27-31.

26. Iwasa $\mathrm{H}$, Aono $\mathrm{T}$, Fukuzawa K. Protective effect of vitamin $\mathrm{E}$ on fetal distress induced by ischemia of the uteroplacental system in pregnant rats. Free Rad Biol Med 1990; 8:393-400.

27. Friel JK, Diehl-Jones WL, Suh M, Tsopmo A, Shirwadkar VP. Impact of iron and vitamin C-containing supplements on preterm human milk: in vitro. Free Radic Biol Med 2007; 42:1591-8.

28. Bogdanovic Pristov J, Spasojevic I, Mikovic Ž, Mandic V, Cerovic N, Spasic M. Antioxidative defense enzymes in placenta protect placenta and fetus in inherited thrombophilia from hydrogen peroxide. Oxid Med Cell Longev 2009; 2:1-5.

29. Brown GC. Reversible binding and inhibition of catalase by nitric oxide. Eur J Biochem 1995; 232:188-91.

30. Beckman JS, Koppenol WH. Nitric oxide, superoxide and peroxynitrite: the good, the bad and ugly. Am J Physiol 1996; 271:1424-37.

31. Nikolic-Kokic A, Stevic Z, Blagojevic D, Davidovic D, Jones DR, Spasic MB. Alterations in anti-oxidative defence enzymes in erythrocytes from sporedic amyotrophic lateral sclerosis (SALS) and familial ALS patients. Clin Chem Lab Med 2006; 44:589-93.

32. Djujic I, Jozanov-Stankov O, Demajo M. Oxidative stress and antioxidant defense markers in the population of Serbia and Montenegro. Yug Physiol Pharmacol Acta 2003; 39:121-8.

33. Gambhir JK, Lali P, Jain AK. Correlation between blood antioxidant levels and lipid peroxidation in rheumatoid arthritis. Clin Biochem 1997; 30:351-5.

34. Nikolic M, Vranic D, Spiric A, Batas V, Nikolic-Kokic A, Radetic P, et al. Could cholesterol bound to haemoglobin be a missing link for the occasional inverse relationship between superoxide dismutase and glutathione peroxidase activities? Biochem Biophys Res Commun 2006; 348:265-70.
35. Miguel F, Augusto AC, Gurgueira SA. Effect of acute vs chronic $\mathrm{H}_{2} \mathrm{O}_{2}$-induced oxidative stress on antioxidant enzyme activities. Free Radic Res 2009; 43:340-7.

36. Georgeson GD, Szony BJ, Shtreitman K, Varga IS, Kovacs A, Kovacs L, et al. Antioxidant enzyme activities are decreased in preterm infants and in neonates born via caesareansection. Eur J Obstet Gynecol Reprod Biol 2002; 103:136-9.

37. Ikeda T, Choi BH, Yee S, Murata Y, Quilligan EJ. Oxidative stress, brain whiter matter damage and intrauterine asphyxia in fetal lambs. Int J Dev Neurosci 1999; 17:1-14.

38. Mover H, Ar A. Antioxidant enzymatic activity in embryos and placenta of rats chronically exposed to hypoxia and hyperoxia. Comp Biochem Physiol 1997; 117:151-7.

39. Murphy MP. How mitochondria produce reactive oxygen species. Biochem J 2009; 417:1-13.

40. Tsukimori K, Fukushima K, Tsushima A, Nakano H. Generation of reactive oxygen species by neutrophils and endothelial cell injury in normal and preeclamptic pregnancies. Hypertension 2005; 46:696-700.

41. Raijmakers MTM, Dechend R, Poston L. Oxidative stress and preeclampsia: Rationale for antioxidant clinical trials. Hypertension 2004; 44:374-80.

42. Cheng L, Harnett KM, Cao W, Liu F, Behar J, Fiocch $\mathrm{C}$, et al. Hydrogen peroxide reduces lower esophageal sphincter tone in human esophagitis. Gastroenterology 2005; 129:1675-85.

43. Clyman RI, Saugstad OD, Mauray F. Reactive oxygen metabolites relax the lamb ductus arteriosus by stimulating prostaglandin production. Circ Res 1989; 64:1-8.

44. Loh S-H, Tsai C-S, Tsai Y, Chen W-H, Hong G-J, Wei J, et al. Hydrogen peroxide-induced intracellular acidosis and electromechanical inhibition in the diseased human ventricular myocardium. Eur J Pharmacol 2002; 443:169-77.

45. Cardoso LM, Colombari DSA, Menani JV, Toney GM, Chianca DA, Colombar E. Cardiovascular responses to hydrogen peroxide into the nucleus tractus solitarius. Am J Physiol Regul Integr Comp Physiol 2009; 297:462-9.

46. Kaandorp JJ, Benders M, Rademaker C, Torrance HL, Oudijk MA, de Haan TR, et al. Antenatal allopurinol for reduction of birth asphyxia induced brain damage ALLO-Trial); a randomized double blind placebo controlled multicenter study. BMC Pregnancy and Childbirth 2010; 10:8.

47. Auclair C, Voisin E. Nitroblue tetrazolium reduction. In: Greenwald RA, ed. Handbook of Methods for Oxygen Radical Research. Boca Raton, FL: CRC Press Inc 1999; 123-32.

48. Pick E, Keisari Y. A simple colorimetric method for the measurement of hydrogen peroxide produced by cells in culture. J Immunol Methods 1980; 38:161-70.

49. Misra HP, Fridovich I. The role of superoxide-anion in the autooxidation of epinephrine and a simple assay for superoxide dismutase. J Biol Chem 1972; 247:3170-5.

50. Beutler E. Catalase. In: Beutler E, ed. Red Cell Metabolism, a Manual of Biochemical Methods. New York: Grune and Stratton 1982; 105-6. 


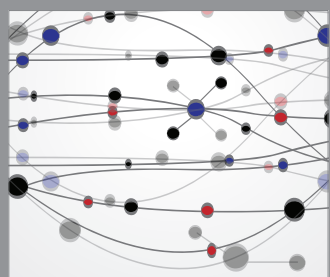

The Scientific World Journal
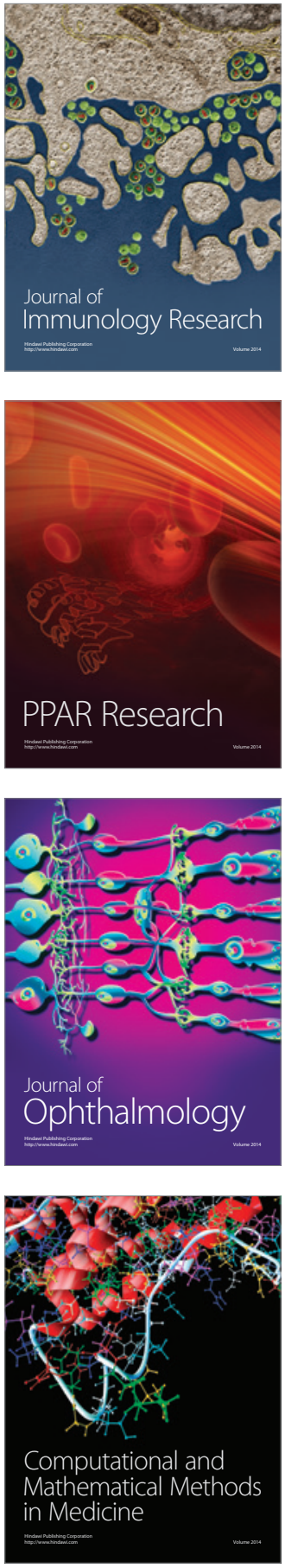

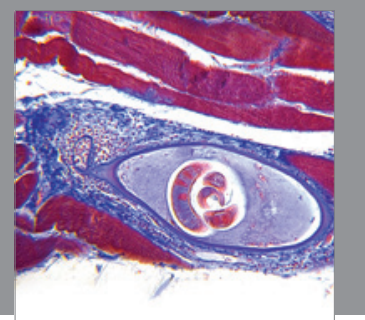

Gastroenterology

Research and Practice
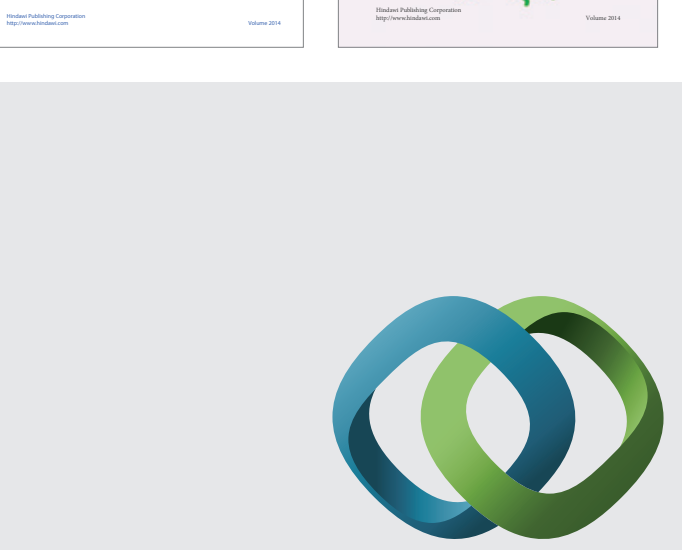

\section{Hindawi}

Submit your manuscripts at

http://www.hindawi.com
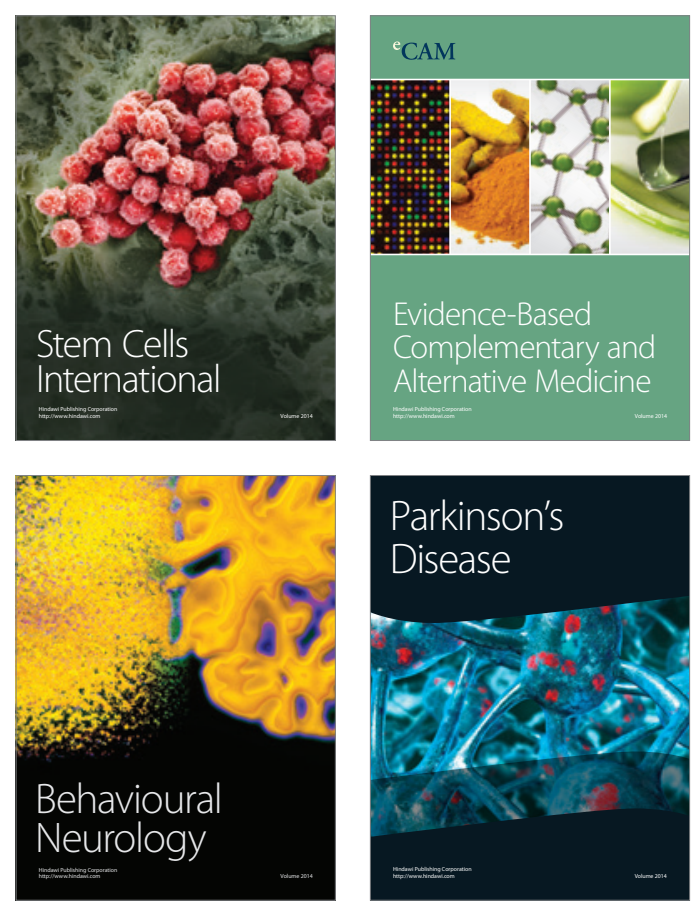

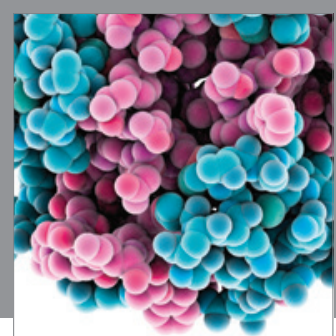

Journal of
Diabetes Research

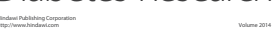

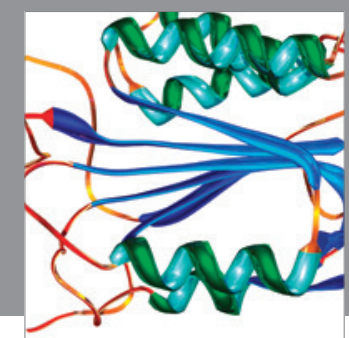

Disease Markers
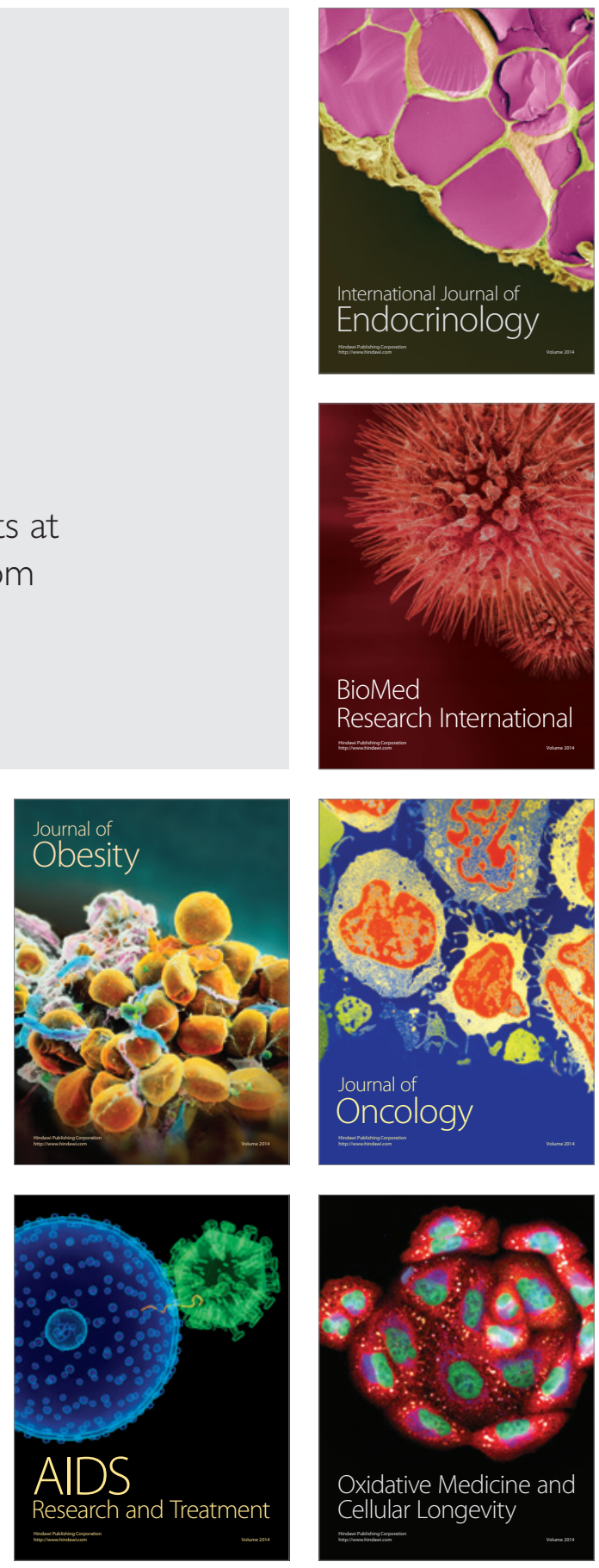